\title{
The role of revision surgery and adjuvant therapy following subtotal resection of osteosarcoma of the spine: a systematic review with meta-analysis
}

\author{
Ganesh M. Shankar, MD, PhD, ${ }^{1}$ Michelle J. Clarke, MD, ${ }^{2}$ Tamir Ailon, MD, MPH, ${ }^{3}$ \\ Laurence D. Rhines, MD, ${ }^{4}$ Shreyaskumar R. Patel, MD, ${ }^{5}$ Arjun Sahgal, MD, ${ }^{6}$ llya Laufer, MD, ${ }^{7}$ \\ Dean Chou, MD, ${ }^{8}$ Mark H. Bilsky, MD, ${ }^{7}$ Daniel M. Sciubba, MD, ${ }^{9}$ \\ Michael G. Fehlings, MD, PhD, FRCSC, ${ }^{10}$ Charles G. Fisher, MD, ${ }^{11}$ Ziya L. Gokaslan, MD, ${ }^{12}$ and \\ John H. Shin, MD'
}

\begin{abstract}
'Department of Neurosurgery, Massachusetts General Hospital, Boston, Massachusetts; '2Department of Neurosurgery, Mayo Clinic, Rochester, Minnesota; ${ }^{3}$ Department of Neurosurgery, University of British Columbia, Vancouver, British Columbia, Canada; ${ }^{4}$ Department of Neurosurgery and ${ }^{5}$ Division of Cancer Medicine, University of Texas MD Anderson Cancer Center, Houston, Texas; ${ }^{\circ}$ Department of Radiation Oncology, Sunnybrook Health Sciences Centre, Toronto, Ontario, Canada; ${ }^{7}$ Department of Neurosurgery, Memorial Sloan Kettering Cancer Center, New York, New York; ${ }^{8}$ Department of Neurosurgery, University of California, San Francisco, California; 'Department of Neurosurgery, Johns Hopkins University, Baltimore, Maryland; ${ }^{10}$ Department of Surgery, University of Toronto, Ontario, Canada; ${ }^{11}$ Department of Orthopedic Surgery, Vancouver Spine Surgery Institute, Vancouver, British Columbia, Canada; and ${ }^{12}$ Department of Neurosurgery, Brown University, Providence, Rhode Island
\end{abstract}

OBJECTIVE Primary osteosarcoma of the spine is a rare osseous neoplasm. While previously reported retrospective studies have demonstrated that overall patient survival is impacted mostly by en bloc resection and chemotherapy, the continued management of residual disease remains to be elucidated. This systematic review was designed to address the role of revision surgery and multimodal adjuvant therapy in cases in which en bloc excision is not initially achieved. METHODS A systematic literature search spanning the years 1966 to 2015 was performed on PubMed, Medline, EMBASE, and Web of Science to identify reports describing outcomes of patients who underwent biopsy alone, neurological decompression, or intralesional resection for osteosarcoma of the spine. Studies were reviewed qualitatively, and the clinical course of individual patients was aggregated for quantitative meta-analysis.

RESULTS A total of 16 studies were identified for inclusion in the systematic review, of which 8 case reports were summarized qualitatively. These studies strongly support the role of chemotherapy for overall survival and moderately support adjuvant radiation therapy for local control. The meta-analysis revealed a statistically significant benefit in overall survival for performing revision tumor debulking $(p=0.01)$ and also for chemotherapy at relapse $(p<0.01)$. Adjuvant radiation therapy was associated with longer survival, although this did not reach statistical significance $(p=0.06)$.

CONCLUSIONS While the initial therapeutic goal in the management of osteosarcoma of the spine is neoadjuvant chemotherapy followed by en bloc marginal resection, this objective is not always achievable given anatomical constraints and other limitations at the time of initial clinical presentation. This systematic review supports the continued aggressive use of revision surgery and multimodal adjuvant therapy when possible to improve outcomes in patients who initially undergo subtotal debulking of osteosarcoma. A limitation of this systematic review is that lesions amenable to subsequent resection or tumors inherently more sensitive to adjuvants would exaggerate a therapeutic effect of these interventions when studied in a retrospective fashion.

https://thejns.org/doi/abs/10.3171/2016.12.SPINE16995

KEY WORDS osteosarcoma; revision surgery; chemotherapy; radiation therapy; systematic review; oncology

ABBREVIATIONS $\mathrm{Cl}=$ confidence interval; COSS = Cooperative Osteosarcoma Study Group; GRADE = Grading of Recommendations Assessment, Development, and Evaluation. SUBMITTED August 22, 2016. ACCEPTED December 12, 2016.

INCLUDE WHEN CITING Published online April 28, 2017; DOI: 10.3171/2016.12.SPINE16995. 
$\mathrm{O}$ STEOSARCOMA represents the most common primary osseous neoplasm, although primary involvement of the spinal column accounts for only $1 \%-3 \%$ of osteosarcomas. Treatment of spinal osteosarcoma represents a considerable challenge, with median survival ranging from 6 to 17 months..$^{16,29}$ Given the rarity of these lesions, most studies concerning osteosarcoma of the spine are limited to small case reports and retrospective case series from single institutions. Nevertheless, such studies have established treatment algorithms involving neoadjuvant chemotherapy and achieving local control via en bloc resection with negative margins. ${ }^{1,13,19,31}$ Aside from improving overall survival, tumor resection may also improve functional status in patients who present with neurological compromise. ${ }^{24}$

Neoadjuvant chemotherapy is used not only to reduce tumor bulk and maximize the chance of achieving a good surgical result, but also to reduce systemic micrometastases. Adjuvant chemotherapy has demonstrable survival benefit, even for patients who undergo intralesional debulking. ${ }^{23,27-29}$ Osteosarcoma is considered a radioresistant tumor, and, as would be expected, conventional radiation therapy alone does not provide an overall survival benefit. ${ }^{2,8,18}$ However, radiation therapy may enhance local control in patients who have undergone surgical debulking or those who demonstrate response to chemotherapy.,11

While most retrospective case series strongly suggest that en bloc resection is the most important determinant for overall survival in osteosarcoma of the spine, there remains uncertainty with regard to the role of adjuvant therapies in patients who undergo subtotal resections. Given that en bloc resections require surgically intensive procedures involving multiple specialists, the patient's first surgical procedure may be needle biopsy, neurological decompression, or intralesional resection, depending on the available medical resources and clinical urgency at the time of presentation. Therefore, it is not uncommon for patients to undergo subtotal resection and subsequently be referred to centers that specialize in the comprehensive and complex surgical and medical management of spinal osteosarcoma. Given the rare nature of these tumors and the implications of subtotal resection, the purpose of this systematic review is to synthesize the limited available studies and ask the following questions: 1) is there an overall survival benefit for pursuing en bloc resection in patients who have previously undergone subtotal resection of osteosarcoma of the spine; and 2) for patients who are not candidates for a subsequent en bloc resection, is there a benefit from systemic chemotherapy or radiation therapy?

\section{Methods}

This systematic review followed Preferred Reporting Items for Systematic Reviews and Meta-Analyses (PRISMA) guidelines. A comprehensive literature search was performed on PubMed, Medline, EMBASE, and Web of Science. The search terms with appropriate Boolean connectors were "osteosarcoma" or "osteogenic sarcoma," "spine," "intralesional" or "subtotal," "revision" or "repeat," and "surgery." Inclusion criteria were the following: studies published in English from 1966 to 2015; those involv- ing human subjects; and clinical trials, case reports, and case series. Exclusion criteria were the following: meeting abstracts or literature reviews; reports not involving osteosarcoma of the spine; studies describing non-osteosarcoma lesions or those not separating osteosarcoma from other sarcoma subtypes; studies containing no description of outcomes following intralesional or subtotal resection, adjuvant chemotherapy, radiation therapy, or additional surgery; and population-based studies. The authors reviewed the full paper of each study identified by the search criteria.

\section{Data Extraction}

From this systematic review we extracted the following data: extent of initial subtotal resection (biopsy, neurological decompression, or intralesional); types of adjuvant therapy (chemotherapy, radiation therapy, and subsequent surgery); and overall survival (status at last follow-up). Distinctions in chemotherapy regimens or radiation therapy protocols were not noted. Studies involving 4 or more patients undergoing subtotal resection were summarized and qualitatively assessed. From studies with less than 4 patients, data were extracted and aggregated into a data set for meta-analysis. Kaplan-Meier survival analysis was performed to determine overall survival of patients following subtotal resection of spinal osteosarcoma. The logrank test was used to determine the impact of systemic chemotherapy, radiation therapy, and revision surgery on patient survival.

\section{Quality of Evidence}

The quality of evidence of the literature derived from our review was scored as high, moderate, low, or very low according to the Grading of Recommendations Assessment, Development, and Evaluation (GRADE) approach ${ }^{17}$ (Supplementary Fig. 1) by consensus of the authors. The relevant studies and associated levels of evidence by GRADE criteria are summarized in Table 1. A multidisciplinary panel of 21 members convened by the AOSpine Knowledge Forum Tumor Group then analyzed the focus questions in the context of this evidence and our metaanalysis. These recommendations were rated as either strong or weak based on the synthesis of the best available evidence and consensus expert opinion via polling of the multidisciplinary panel. Given the uniformity of "low" and "very low" quality of evidence, no significant discrepancies in strength of recommendations were encountered during this poll.

\section{Results}

\section{Search Results of the Systematic Literature Review}

The comprehensive literature search to address these questions yielded 25 articles on PubMed, 32 on Medline and EMBASE, and 72 on ISI/Web of Science. Exclusion criteria listed in the methods section reduced these lists to 16 articles (Table 1). Of these 16 articles, a total of 8 described the outcomes of 4 or more patients with osteosarcoma of the spine, and these were used for qualitative analysis (Fig. 1). Extracted data from these studies were aggregated with the other smaller case reports for the meta-analysis (Table 1). 

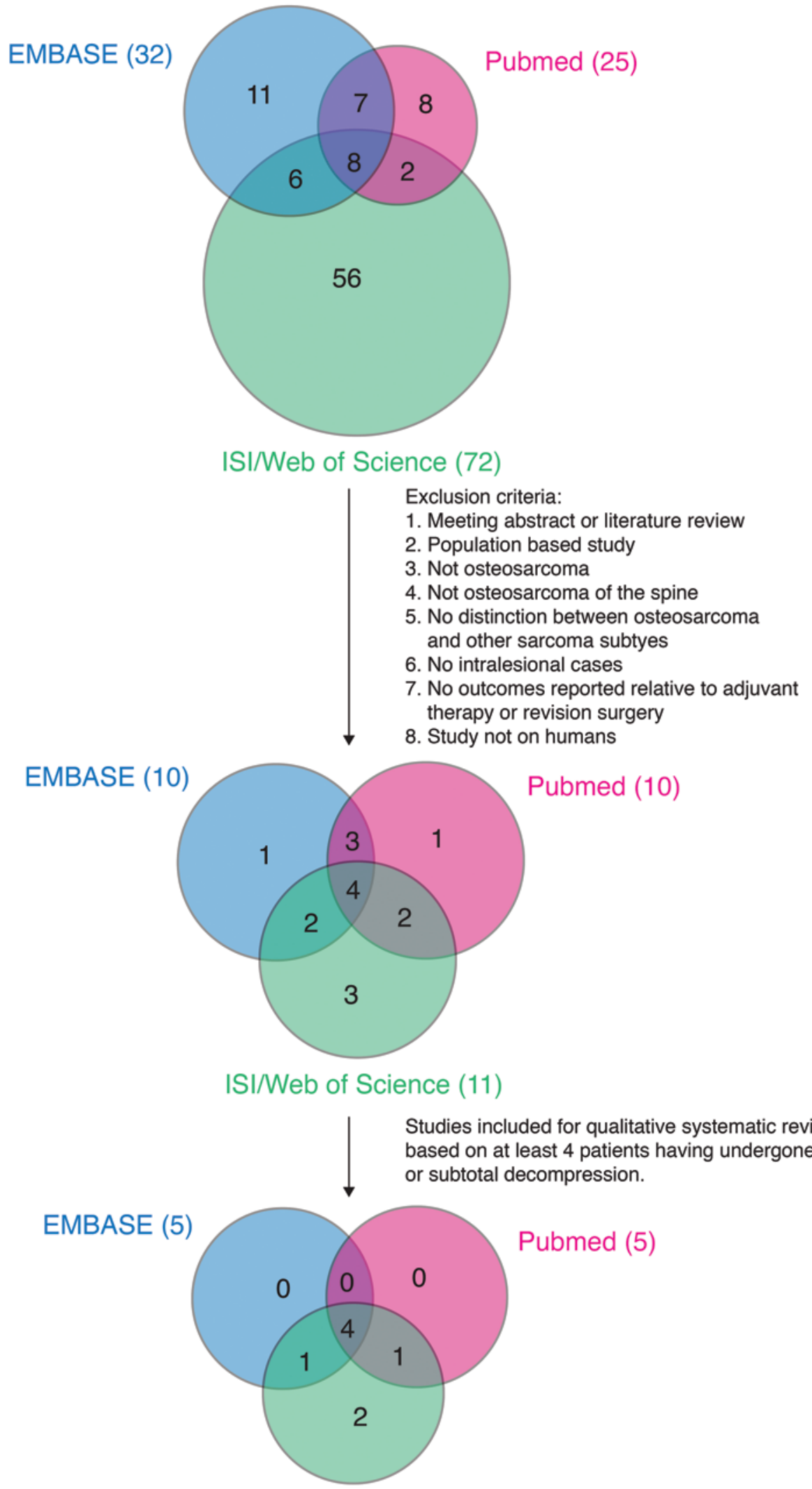

ISI/Web of Science (8)

FIG. 1. Diagrammatic representation of studies selected from systematic review and for meta-analysis. 
TABLE 1. Characteristics of studies identified in systematic review of osteosarcoma of the spine

\begin{tabular}{|c|c|c|c|c|c|}
\hline \multirow[b]{2}{*}{ Authors \& Year } & \multirow{2}{*}{$\begin{array}{l}\text { Spine Osteosarcoma } \\
\text { Sample Size }\end{array}$} & \multicolumn{3}{|l|}{ No. of Patients } & \multirow{2}{*}{$\begin{array}{c}\text { GRADE Evidence } \\
\text { Quality }\end{array}$} \\
\hline & & Biopsy or Subtotal Decompression & Chemo & RT & \\
\hline Shives et al., 1986 & 27 & 27 & 5 & 21 & Low \\
\hline Sundaresan et al., 1988 & 24 & 18 & 17 & 21 & Low \\
\hline Tasdemiroglu et al., 1996 & 1 & 1 & 1 & 1 & Very low \\
\hline McCormick, 1996 & 1 & 1 & 0 & 0 & Very low \\
\hline Cohen et al., 2002 & 1 & 1 & 1 & 1 & Very low \\
\hline Ozaki et al., 2002 & 22 & 17 & 22 & 8 & Low \\
\hline Gore et al., 2003 & 1 & 1 & 1 & 1 & Very low \\
\hline Delaney et al., 2005 & 8 & ND & ND & 8 & Low \\
\hline Schoenfeld et al., 2010 & 26 & 19 & 25 & 24 & Low \\
\hline Turel et al., 2012 & 1 & 1 & 1 & 1 & Very low \\
\hline Schwab et al., 2012 & 17 & 8 & 17 & 8 & Low \\
\hline Chan et al., 2012 & 1 & 1 & 1 & 1 & Very low \\
\hline Druschel et al., 2012 & 2 & 2 & 1 & 1 & Very low \\
\hline Lim et al., 2013 & 10 & 3 & 9 & 9 & Low \\
\hline Feng et al., 2013 & 16 & 9 & 16 & 14 & Low \\
\hline Zils et al., 2013 & 20 & 8 & 20 & 13 & Low \\
\hline
\end{tabular}

Chemo = chemotherapy; ND = not denoted; RT = radiation therapy.

\section{Reports Addressing the Role of Revision Surgery}

Studies reporting the results of revision tumor debulking are highly limited. ${ }^{5,12,25}$ The case series by Druschel et al. describes the outcomes of 2 patients who had previously undergone intralesional resection followed by marginal en bloc 4-level resection. One patient received neoadjuvant chemotherapy prior to the en bloc resection, and the other patient received adjuvant radiation therapy. No evidence of tumor recurrence was noted in either patient at 8 and 17 months. The study of Schoenfeld et al. was a single-institution retrospective case series of 26 patients who underwent management of osteosarcoma of the spine. Within this study, 3 patients had undergone surgical decompression following biopsy or subtotal tumor debulking. At the time of recurrence, 1 patient underwent en bloc resection with a contaminated tumor margin, and 2 underwent intralesional resection. All patients received adjuvant chemotherapy and radiation therapy and were alive and disease free at the last follow-up evaluation (22-51 months). A case report by Chan et al. described a patient who developed recurrence following intralesional resection of osteosarcoma involving C-3. The patient underwent subsequent debulking of the recurrent tumor and received adjuvant chemotherapy for 40 weeks. She was disease-free at 12 months following the second resection.

\section{Studies Addressing the Role of Adjuvant Chemotherapy and Radiation Therapy}

While no case series identified by the search exclusively assessed the effects of adjuvant therapies in patients following subtotal debulking of osteosarcoma of the spine, each study described in this section includes at least 1 patient who underwent biopsy, decompression, or intralesional resection (Table 1).

Shives et al. represents one of the first retrospective case series from an era that predates the adoption of en bloc resection and combination chemotherapy as the main therapeutic options for osteosarcoma. ${ }^{28}$ This report details the outcome of 27 patients treated at the Mayo Clinic from 1909 to 1980 for osteosarcoma of the spine, including 11 involving the sacrum. Patients were initially managed by biopsy, laminectomy, or intralesional resection, and some were subsequently treated by adjuvant chemotherapy and/ or radiation therapy. Median overall survival in this cohort was 10 months. Although no formal statistical analysis was performed, the authors concluded that aggressive multimodal therapy with maximal resection, chemotherapy, and radiation therapy would be indicated based on this experience.

Sundaresan et al. described the outcome of 24 patients with osteosarcoma of the spine over a 35 -year period..$^{29}$ The first group of 13 patients were mostly treated by biopsy or intralesional resection $(\mathrm{n}=11)$ followed by radiation therapy $(\mathrm{n}=12)$, whereas the second, more "recent" group $(\mathrm{n}=11)$, were predominantly treated with en bloc resection $(n=7)$, adjuvant chemotherapy $(n=11)$, and radiation therapy $(n=9)$. The latter group had a median survival 3 times longer than that of the former (18 vs 6 months), leading the authors to conclude that complete surgical excision in combination with chemotherapy provides the strongest survival benefit. Detailed information presented in this study on 4 patients who underwent subtotal resection of their tumors was included in our meta-analysis.

The Cooperative Osteosarcoma Study Group (COSS) reported by Ozaki et al. describes the experience of 22 patients with osteosarcoma of the spine (15 involving the sacrum and 7 at other sites) with a median follow-up of 47 months. ${ }^{23}$ All patients received chemotherapy according to a COSS protocol. In this study, 7 patients underwent intralesional resection, 2 underwent decompression by 
laminectomy, and 8 underwent biopsy alone. The authors report that there was a statistically significant benefit in overall survival for 5 patients who underwent en bloc resection as compared with 17 who underwent intralesional resection or no surgery $(\mathrm{p}=0.033)$. The increased survival in the 10 patients who received adjuvant radiation therapy did not reach statistical significance $(p=0.059)$. Six of the 17 patients who underwent subtotal resections or biopsy only received radiation therapy. The authors concluded that patients should be treated with combination therapy and marginal excision, when possible, and that adjuvant radiation therapy may provide a survival benefit. Zils et al. reported an updated experience from the COSS group of 20 patients with osteosarcoma of the mobile spine. ${ }^{33}$ All patients were treated with neoadjuvant and postoperative chemotherapy. Five-year overall survival in this cohort was $60 \%$. Of this cohort, 5 patients underwent intralesional resection and were included in the meta-analysis presented below.

Delaney et al. performed a retrospective review of 41 patients who all received adjuvant radiation therapy for osteosarcoma involving any bone. ${ }^{11}$ Patients received $10-80$ Gy (median 66 Gy) and 23 of these patients received radiation therapy by proton beam. Eight of these patients had spinal involvement, but the outcomes analysis did not separate this cohort from the other 33 patients. The 5-year mean overall survival rate was $74 \% \pm 16 \%$ for patients with subtotal resection and $25 \% \pm 22 \%$ for patients who underwent biopsy alone. Local disease control at 5 years appeared to be better for patients receiving > 55 Gy $(71 \%$ $\pm 9 \%)$ compared with those who received $<55$ Gy $(54 \% \pm$ $20 \%$ ). The 5-year mean local control rate was $67 \% \pm 27 \%$ for the 3 patients who had positive margins. The authors surmised that radiation therapy may facilitate local control when en bloc resection with negative margins is not feasible.

The study by Schwab et al. was a single-institution retrospective study describing the outcomes of 17 patients with osteosarcoma of the mobile spine over a median follow-up period of 38 months. ${ }^{26}$ All patients received neoadjuvant chemotherapy. Eight patients underwent subtotal resection ( 2 for biopsy and 6 for intralesional resection), of whom 6 received adjuvant radiation therapy. Median survival following en bloc resection was 77.3 months versus 16.8 months following subtotal resection. The authors concluded that en bloc resection is associated with superior overall survival.

Feng et al. conducted a retrospective review of 16 patients treated by intralesional resection $(n=9)$ or total en bloc spondylectomy $(n=7)$ followed by adjuvant chemotherapy. The majority of these patients $(n=14)$ also received adjuvant radiation therapy. ${ }^{14}$ Of the 9 patients who underwent intralesional resection, 5 were found to have local recurrence and 5 developed systemic metastases over an average follow-up of 18.8 months. The 2 patients who did not receive adjuvant radiation therapy developed both local recurrence and distal metastases. Although no statistical analysis was performed, the authors interpreted their experience as supporting neoadjuvant chemotherapy and adjuvant radiation therapy to improve local and distal control when marginal resection is not possible.

\section{Meta-Analyses of Adjuvant Therapies Following Subtotal Resection of Osteosarcoma of the Spine}

As can be seen above, most studies on this topic represent the experience of single institutions managing patients with osteosarcoma of the spine. To overcome this limitation we attempted to extract and aggregate data on the clinical course of individual patients and conduct a meta-analysis of their outcome. These data are presented in Supplementary Table 1.5,7,15,20,22,30,32

Kaplan-Meier survival curves comparing outcomes for patients who underwent subtotal resection followed by revision surgery, radiation therapy, or chemotherapy are shown in Fig. 2. Median overall survival with 95\% confidence intervals (CIs) is listed in Table 2. While there was a trend toward improved survival with subtotal decompression as compared with biopsy alone as the initial surgical intervention, this difference did not reach statistical significance ( $\mathrm{p}=0.10$; Fig. 2A). However, there was a significant benefit in overall survival noted in the 7 patients who underwent revision surgery following prior subtotal decompression as compared with 82 patients who did not undergo further surgery ( $\mathrm{p}=0.01$; Fig. 2B). Of note, given the small number of patients, this analysis is not powered to detect differences between revision intralesional and en bloc resection.

The benefit derived from chemotherapy following initial subtotal resection of osteosarcoma also reached statistical significance (median overall survival of 24 months vs 10 months for no systemic chemotherapy, $\mathrm{p}<0.01$; Fig. $2 \mathrm{C})$. Adjuvant radiation therapy demonstrated a trend toward improved overall survival, but this difference did not reach statistical significance (24 vs 17 months, $\mathrm{p}=0.06$; Fig. 2D).

\section{Discussion}

Landmark studies that revolutionized the approach and ultimately the survival of patients with osteosarcoma demonstrated that en bloc resection should be performed when surgically feasible.,13,31 Despite the moderate chemosensitivity of these tumors ${ }^{23}$ and mild stabilization by radiation therapy, ${ }^{11}$ achieving a marginal resection as the initial treatment has borne out as a strong predictor of survival in multiple studies. ${ }^{9,14,23,26,27}$ However, in some patients an en bloc resection may not be possible at the initial presentation due to a lack of comprehensive multispecialty resources, anatomical limitations, or inconclusive pathology on initial specimen evaluation. Although the number of patient outcomes in the literature is limited following staged resection, this systematic review suggests a survival benefit with revision surgery. Given the low number of patients reported in the literature, it remains unclear whether marginal resection is superior to intralesional debulking for residual or recurrent tumor.

Both the systematic review ${ }^{14,23,28,29}$ and meta-analysis support the use of chemotherapy as a neoadjuvant or adjuvant treatment. This is consistent with the known chemosensitivity of the tumor and from prior studies assessing the response of osteosarcoma involving the limbs. ${ }^{21}$ Osteosarcoma is considered a radioresistant neoplasm, but previous studies have suggested that adjuvant radiotherapy 

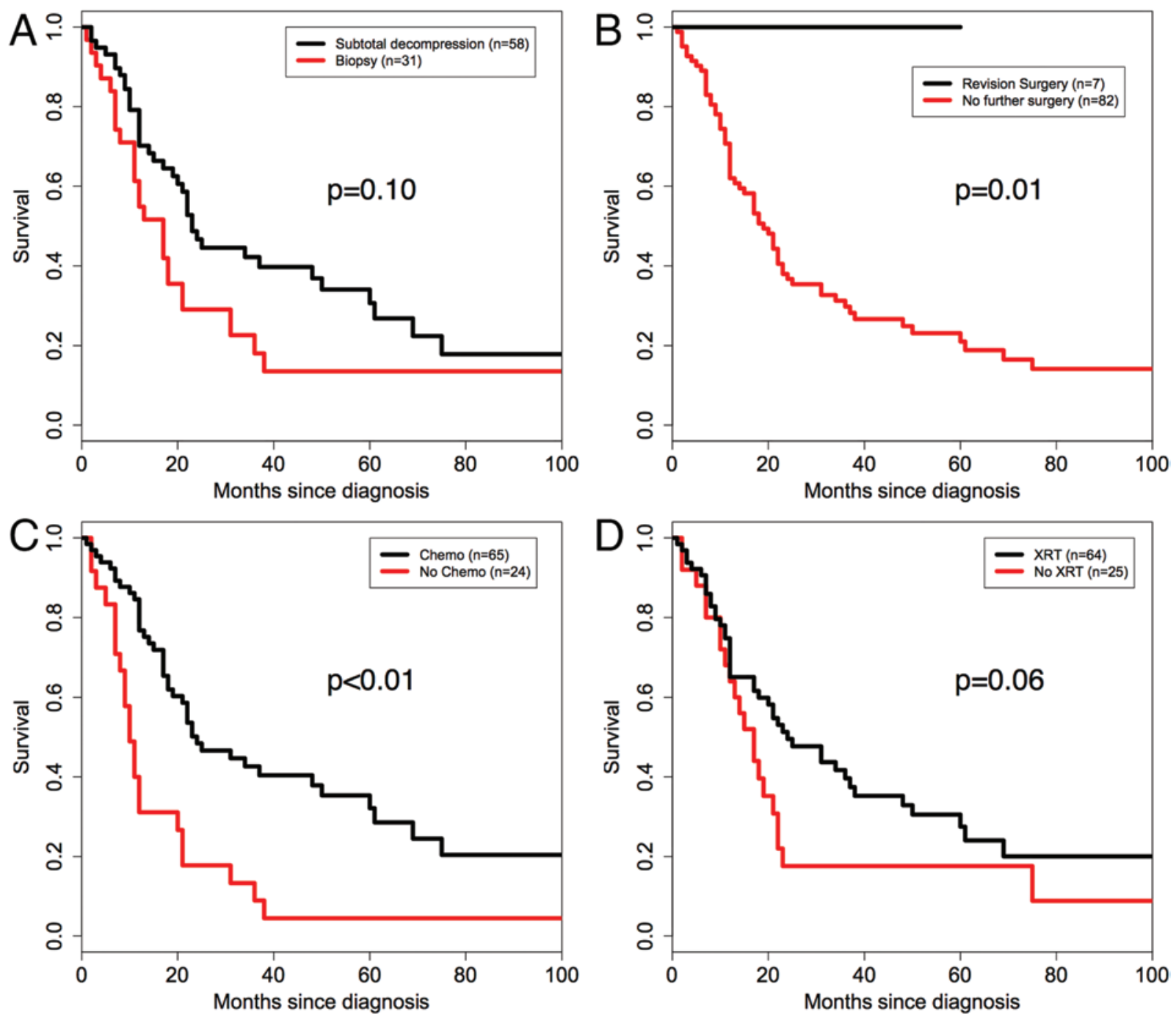

FIG. 2. Kaplan-Meier survival curves of patients with osteosarcoma of the spine following biopsy or subtotal decompression. A: Overall survival comparing biopsy and subtotal decompression (laminectomy or intralesional resection). B: Revision surgery for residual or recurrent lesions versus no further surgical intervention. C: Neoadjuvant or adjuvant chemotherapy (Chemo) compared with no chemotherapy. D: Adjuvant radiation therapy (XRT) versus no radiation therapy.

may facilitate local control when wide or marginal resection is not possible. ${ }^{11}$ Our meta-analysis also noted longer overall survival in patients who were treated with adjuvant radiation therapy following biopsy or subtotal decompression, but this did not reach statistical significance. It is possible that administering higher radiation doses (> 66 Gy) to the remaining tumor volume and margins by proton beam therapy, intensity modulated radiotherapy, or carbon ion therapy may provide improved local control. ${ }^{6,10}$ An ongoing single-center trial (no. NCT01005043; clinicaltrials.gov) will assess the safety and efficacy of proton beam therapy for unresectable osteosarcoma in a target of 20 patients. $^{3}$ Similarly, while chemotherapy protocols have historically incorporated general cytotoxic and platinum-based compounds, ongoing clinical trials examining various forms of targeted therapy and stimulation of immune response may alter the effect size of systemic therapies on local control and overall survival.

An inherent bias that cannot be accounted for in the review of retrospective studies is that lesions that are amenable to subsequent resection or reported responders to chemotherapy or radiation therapy are predisposed to im-

TABLE 2. Median survival with following treatments after biopsy or subtotal decompression

\begin{tabular}{cccccc}
\hline Treatment Rendered & Chemo & RT & Revision Surgery & Biopsy Only & Subtotal Decompression \\
\hline Yes & $24(19-60)$ & $24(18-48)$ & Not reached & $17(11-31)$ & $23(20-60)$ \\
\hline No & $10(9-21)$ & $17(12-22)$ & $19(14-24)$ & & \\
\hline
\end{tabular}

Data given as median months $(95 \% \mathrm{Cls})$. 
proved survival and local control by the underlying pathobiology and aggressiveness of those lesions. As a result of this bias, the systematic review and meta-analysis presented herein would be expected to show an exaggerated estimate of the beneficial effect of surgery, chemotherapy, and radiation therapy. Given the rarity of these neoplasms, it is unlikely that a controlled trial would be powered to address these issues in a scientifically rigorous manner. However, in support of the interpretations of the present study are findings from a study of Ewing's sarcoma, another osseous sarcoma subtype, which also support an aggressive multimodal approach to treatment. ${ }^{27}$

\section{Synthesis of Systematic Review}

This systematic review supports the use of multimodal therapy following subtotal decompression of osteosarcoma. Specifically, low-quality evidence from observational studies supports the use of chemotherapy, and very low quality evidence from case reports suggests that additional resection may improve overall survival. Given the rarity of these tumors, prospective multicenter trials may further substantiate these observations.

Is there an overall survival benefit for pursuing en bloc resection (marginal/wide margins) in patients who have previously undergone subtotal resection of osteosarcoma of the spine? The strength of recommendation for this is weak, and the quality of evidence is very low. In revision surgery after initial subtotal resection or local recurrence of spinal osteosarcoma, where feasible, en bloc (marginal/ wide margins) can be considered an option as it may confer a survival advantage as compared with no or intralesional surgery.

For patients who are not candidates for a subsequent en bloc resection, is there a benefit from systemic chemotherapy or adjuvant radiation therapy? The strength of recommendation for this is weak, and the quality of evidence is low. Systemic chemotherapy should be considered after subtotal resection of spinal osteosarcoma. Insufficient data exist to direct the specific chemotherapeutic regimen used. Adjuvant radiotherapy can be considered after subtotal resection of spinal osteosarcoma. Very low quality evidence suggests that it may be useful to improve the rate of local control after subtotal resection, although no clear survival advantage has been demonstrated.

\section{Conclusions}

Revision surgery after initial subtotal resection of spinal osteosarcoma, where feasible, can be considered as it may confer a survival advantage as compared with no surgery. Adjuvant chemotherapy should be considered after subtotal resection of spinal osteosarcoma based on low quality of evidence that demonstrates a substantial survival benefit. Adjuvant radiotherapy can be considered after subtotal resection of spinal osteosarcoma with low-quality evidence suggesting improved local control of disease.

\section{Acknowledgments}

This study was made possible by the AOSpine Knowledge Tumor Forum. AOSpine is a clinical division of the AO Founda- tion, an independent medically guided nonprofit organization. The AOSpine Knowledge Forums are pathology-focused working groups acting on behalf of AOSpine in their domain of scientific expertise. Each forum consists of a steering committee of up to 10 international spine experts who meet on a regular basis to discuss research, assess the best evidence for current practices, and formulate clinical trials to advance spine care worldwide. Study support is provided directly through AOSpine's Research department.

\section{References}

1. Abe E, Sato K, Tazawa H, Murai H, Okada K, Shimada Y, et al: Total spondylectomy for primary tumor of the thoracolumbar spine. Spinal Cord 38:146-152, 2000

2. Beck JC, Wara WM, Bovill EG Jr, Phillips TL: The role of radiation therapy in the treatment of osteosarcoma. Radiology 120:163-165, 1976

3. Blattmann C, Oertel S, Schulz-Ertner D, Rieken S, Haufe $\mathrm{S}$, Ewerbeck V, et al: Non-randomized therapy trial to determine the safety and efficacy of heavy ion radiotherapy in patients with non-resectable osteosarcoma. BMC Cancer 10:96, 2010

4. Caceres E, Zaharia M, Valdivia S, Misad O, de la Flor J, Tejada F, et al: Local control of osteogenic sarcoma by radiation and chemotherapy. Int J Radiat Oncol Biol Phys 10:35-39, 1984

5. Chan KY, Sun TF, Kam KM, Shing MK, Poon WS: Cervical spinal osteosarcoma in an adolescent. J Clin Neurosci 19:1172-1174, 2012

6. Ciernik IF, Niemierko A, Harmon DC, Kobayashi W, Chen YL, Yock TI, et al: Proton-based radiotherapy for unresectable or incompletely resected osteosarcoma. Cancer 117:4522-4530, 2011

7. Cohen ZR, Fourney DR, Marco RA, Rhines LD, Gokaslan ZL: Total cervical spondylectomy for primary osteogenic sarcoma. Case report and description of operative technique. J Neurosurg 97 (3 Suppl):386-392, 2002

8. de Moor NG: Osteosarcoma a review of 72 cases treated by megavoltage radiation therapy, with or without surgery. $\mathbf{S}$ Afr J Surg 13:137-146, 1975

9. Dekutoski MB, Clarke MJ, Rose P, Luzzati A, Rhines LD, Varga PP, et al: Osteosarcoma of the spine: prognostic variables for local recurrence and overall survival, a multicenter ambispective study. J Neurosurg Spine 25:59-68, 2016

10. DeLaney TF, Liebsch NJ, Pedlow FX, Adams J, Dean S, Yeap BY, et al: Phase II study of high-dose photon/proton radiotherapy in the management of spine sarcomas. Int $\mathbf{J}$ Radiat Oncol Biol Phys 74:732-739, 2009

11. DeLaney TF, Park L, Goldberg SI, Hug EB, Liebsch NJ, Munzenrider JE, et al: Radiotherapy for local control of osteosarcoma. Int J Radiat Oncol Biol Phys 61:492-498, 2005

12. Druschel C, Disch AC, Melcher I, Engelhardt T, Luzzati A, Haas NP, et al: Surgical management of recurrent thoracolumbar spinal sarcoma with 4-level total en bloc spondylectomy: description of technique and report of two cases. Eur Spine J 21:1-9, 2012

13. Enneking WF, Spanier SS, Goodman MA: A system for the surgical staging of musculoskeletal sarcoma. Clin Orthop Relat Res (153):106-120, 1980

14. Feng D, Yang X, Liu T, Xiao J, Wu Z, Huang Q, et al: Osteosarcoma of the spine: surgical treatment and outcomes. World J Surg Oncol 11:89, 2013

15. Gore L, Greffe BS, Rothenberg SS, Erickson M, Schreiber DP, Handler MH: Long-term survival after intralesional resection and multi-modal therapy of thoracic spine osteosarcoma. Med Pediatr Oncol 40:400-402, 2003

16. Groves ML, Zadnik PL, Kaloostian P, Sui J, Goodwin CR, Wolinsky JP, et al: Epidemiologic, functional, and oncologic 
outcome analysis of spinal sarcomas treated surgically at a single institution over 10 years. Spine J 15:110-114, 2015

17. Guyatt G, Gutterman D, Baumann MH, Addrizzo-Harris D, Hylek EM, Phillips B, et al: Grading strength of recommendations and quality of evidence in clinical guidelines: report from an American College of Chest Physicians task force. Chest 129:174-181, 2006

18. Jenkin RD, Allt WE, Fitzpatrick PJ: Osteosarcoma. An assessment of management with particular reference to primary irradiation and selective delayed amputation. Cancer 30:393-400, 1972

19. Liljenqvist U, Lerner T, Halm H, Buerger H, Gosheger G, Winkelmann W: En bloc spondylectomy in malignant tumors of the spine. Eur Spine J 17:600-609, 2008

20. Lim JBT, Sharma H, MacDuff E, Reece AT: Primary osteosarcoma of the spine: a review of 10 cases. Acta Orthop Belg 79:457-462, 2013

21. Link MP, Goorin AM, Miser AW, Green AA, Pratt CB, Belasco JB, et al: The effect of adjuvant chemotherapy on relapse-free survival in patients with osteosarcoma of the extremity. N Engl J Med 314:1600-1606, 1986

22. McCormick PC: Surgical management of dumbbell and paraspinal tumors of the thoracic and lumbar spine. Neurosurgery 38:67-75, 1996

23. Ozaki T, Flege S, Liljenqvist U, Hillmann A, Delling G, Salzer-Kuntschik M, et al: Osteosarcoma of the spine: experience of the Cooperative Osteosarcoma Study Group. Cancer 94:1069-1077, 2002

24. Rao G, Suki D, Chakrabarti I, Feiz-Erfan I, Mody MG, McCutcheon IE, et al: Surgical management of primary and metastatic sarcoma of the mobile spine. J Neurosurg Spine 9:120-128, 2008

25. Schoenfeld AJ, Hornicek FJ, Pedlow FX, Kobayashi W, Garcia RT, DeLaney TF, et al: Osteosarcoma of the spine: experience in 26 patients treated at the Massachusetts General Hospital. Spine J 10:708-714, 2010

26. Schwab J, Gasbarrini A, Bandiera S, Boriani L, Amendola L, Picci P, et al: Osteosarcoma of the mobile spine. Spine (Phila Pa 1976) 37:E381-E386, 2012

27. Sciubba DM, Okuno SH, Dekutoski MB, Gokaslan ZL: Ewing and osteogenic sarcoma: evidence for multidisciplinary management. Spine (Phila Pa 1976) 34 (22 Suppl):S58 S68, 2009

28. Shives TC, Dahlin DC, Sim FH, Pritchard DJ, Earle JD: Osteosarcoma of the spine. J Bone Joint Surg Am 68:660 668,1986

29. Sundaresan N, Rosen G, Huvos AG, Krol G: Combined treatment of osteosarcoma of the spine. Neurosurgery 23:714719,1988

30. Tasdemiroglu E, Bagatur E, Ayan I, Darendeliler E, Patchell RA: Primary spinal column sarcomas. Acta Neurochir (Wien) 138:1261-1266, 1996
31. Tomita K, Kawahara N, Baba H, Tsuchiya H, Fujita T, Toribatake Y: Total en bloc spondylectomy. A new surgical technique for primary malignant vertebral tumors. Spine (Phila Pa 1976) 22:324-333, 1997

32. Turel MK, Joseph V, Singh V, Moses V, Rajshekhar V: Primary telangiectatic osteosarcoma of the cervical spine. J Neurosurg Spine 16:373-378, 2012

33. Zils K, Bielack S, Wilhelm M, Werner M, Schwarz R, Windhager R, et al: Osteosarcoma of the mobile spine. Ann Oncol 24:2190-2195, 2013

\section{Disclosures}

Dr. Rhines has served as a consultant to Stryker and Globus. Dr. Sahgal has served as a consultant to Varian Medical Systems and Hoffman-La Roche Limited; has received compensation for educational seminars from Medtronic, Elekta AB, Accuray Inc., and Varian Medical Systems; has received a research grant from Elekta $\mathrm{AB}$; and has received travel accommodations/expenses from Medtronic, Elekta, and Varian. Dr. Laufer has served as a consultant to DePuy/Synthes, Globus, and SpineWave. Dr. Chou has served as a consultant to Medtronic, Globus, and Orthofix; and has received royalties from Globus. Dr. Sciubba has served as a consultant to Medtronic, DePuy Synthes, Globus, Orthofix, and Stryker. Dr. Fisher has served as a consultant to Medtronic and NuVasive; has received fellowship support paid to his institution from Medtronic and AOSpine (OREF grant); and has received royalties from Medtronic.

\section{Author Contributions}

Conception and design: Shin, Shankar, Gokaslan. Acquisition of data: Shin, Shankar. Analysis and interpretation of data: all authors. Drafting the article: all authors. Critically revising the article: all authors. Reviewed submitted version of manuscript: all authors. Statistical analysis: Shin, Shankar. Administrative/technical/material support: Shin, Shankar. Study supervision: Shin, Shankar.

\section{Supplemental Information \\ Online-Only Content}

Supplemental material is available with the online version of the article.

Supplementary Materials. https://thejns.org/doi/suppl/10.3171/ 2016.12.SPINE16995.

\section{Correspondence}

John H. Shin, Department of Neurosurgery, Massachusetts General Hospital, 15 Parkman St., Boston, MA 02114. email: shin. john@mgh.harvard.edu. 